\title{
MODELING AND SIMULATION OF FUZZY PID CONTROLLERS FOR A SUBMERGED ARC FERROSILICON FURNACE
}

\author{
G. Shabib \\ Faculty of Energy Engineering, South Valley University, Aswan, 81528, \\ Egypt, E-mail: gabershabib@yahoo.com
}

(Received August 15, 2011 Accepted March 26, 2012)

This paper investigates the control strategy for the electrical energy input to three phase electric arc ferrosilicon furnace. The classical PD fuzzy logic controller has two inputs. These inputs are the error in the V-I characteristic and the rate of the error in V-I characteristic. When the simulation result of this controller is compared with conventional PD type, it was shown that requires steady state accuracy. This paper is concerned with incorporating the integral property to the classic fuzzy PD controller. The result is a nonlinear fuzzy PID controller eliminates the steady state error resulted from the classic fuzzy $P D$ actions. In this paper, the submerged arc ferrosilicon furnace is described by the heat transfer system, the electrical system equipments and the dynamics from the electrode positions to the electrode currents. The proposed control design methodology is tested on the model of submerged arc ferrosilicon furnace $\mathrm{FeSi}$ via simulation. The simulation work is carried out using simple environment via computer program written using $C++$ language. The obtained results guarantee the potential of the proposed control methodology to add self autonomy to the system behavior.

KEYWORDS: Arc resistances; Electrodes; Fuzzy Logic control; Industrial process, Model; PID controllers.

\section{INTRODUCTION}

Electric arc furnaces are used to produce $\mathrm{FeSi}$ by melting the raw materials (mainly quartz, coal, and coke) using electrical supply as main energy input [1-6]. The electrode system, connected to the electrical supply as shown in Fig. (1) is used to convert electrical energy into extensive heat by means of high current arcs cause the solid scrap to be transformed into liquid state.

The main objective in an electric arc furnace industry is maximum production of high quality $\mathrm{FeSi}$ at the lowest possible cost. Electric current in the electrodes will remain constant if the lengths of the electric arcs are constant. The electrode system under investigation in this study is mainly responsible for the vertical adjustments of the electrode tip displacement according to specified set points, to ensure that the arc lengths remain as constant as possible. Arc current is mainly used as the control variable in an industrial electric arc furnace because of its direct relation with the lengths of the electric arcs.

Most modern three-phase electric furnaces make use of some form of feedback control strategy for the automatic control of the electrical energy input [7-15]. One of the control strategy utilized is the use of PID controllers which can adjust the lengths 
of the electric arcs relative to some set-point. PID controller is well established in many classical control systems and it is often used as a benchmark against other types of controllers [16]. PID controllers are considered as linear controller, for this reason it is not usually suitable for strongly nonlinear systems. Fuzzy PID controllers are often mentioned as an alternative to classical fuzzy $P D$ controllers in such cases [17-19].

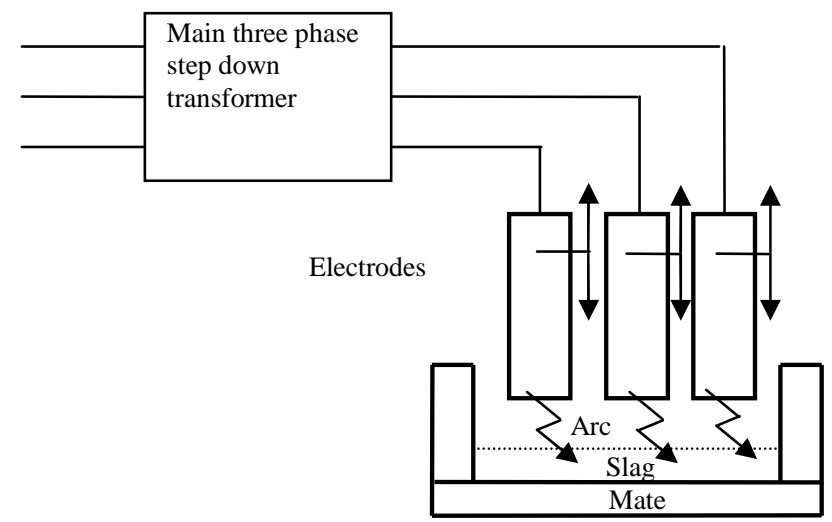

Fig. (1) A Physical model of EAF system

Fuzzy PID controllers used in a submerged arc ferrosilicon furnace are found in [20]. Various structures for fuzzy $P I D$ (including $P I$ and $P D$ ) controllers are found in $[21,22]$. Fuzzy $P I$ control is known to be more practical than fuzzy $P D$ because it is difficult for the fuzzy $P D$ to remove steady state error [23]. The fuzzy $P I$ control, however, it gives poor performance in transient response for higher order processes due to the internal integration operation, but it eliminates the steady state error resulted from the proportional gain. Thus, in practice the fuzzy PID controllers are more useful. To obtain proportional, integral and derivative control action all together, it is intuitive and convenient to combine $P I$ and $P D$ actions together to form a Fuzzy $P I D$ controller. Another way of constructing a fuzzy PID controller is achieved by summing the fuzzy $P D$ controller output to an integrator connected in parallel with it [22]. This fuzzy PID controller utilized a single rule-base. In this paper the second type is used in our study.

\section{ARC FURNANCE SYSTEM MODEL}

There are two subsystems in the electrical arc furnace, electrical and metallurgical system. The electrical system supplies energy to the metallurgical system and the metallurgical system gives conductivity back to electrical system [1]. The electrical subsystem is described by a set of equations representing the electrical system, while the metallurgical subsystem is very different, as it involves gas and particle flow, reaction kinetics, etc. It is more difficult to establish a set of equations that describe the process to the relevant level of accuracy [2, 3]. In modeling the electric arc furnace, many factors are to be considered. These are heat transfer, walls of furnace and the heat losses into external medium.

- The walls of the furnace have ideal heat insulation and there are no losses into surrounding. The transfer function of heat balance is as follows: 
$\rho C V \frac{d \theta}{d t}=H_{1}-H_{2}$

Where: $\rho$ is the material density, $\operatorname{ton} / \mathrm{m}^{3}, C$ is the specific heat, Mcal / deg .ton, $V$ is the volume of the furnace, $m^{3}, \theta$ is the temperature in zone, ${ }^{\circ} c$, $H_{1}=Q_{1} \rho_{1} C \theta_{1}$ is the heat flow with material $Q_{1}$ Mcal/hour, $Q_{1}$ is the flow input $\mathrm{m}^{3}$ /hour, $\mathrm{H}_{2}=Q_{2} \rho_{2} \mathrm{C \theta}_{2}$ is the heat flow with material $Q_{2}$ Mcal/hour, $Q_{2}$ is the flow output $\mathrm{m}^{3}$ /hour. The material flow for input and output are assumed to be constant $\left(Q_{l}\right.$ $\left.=Q_{2}=Q\right)$ and the temperature $\theta(t)$ is equal to $\theta_{2}(t)$.

$\frac{\theta(S)}{H_{1}(S)}=\frac{K}{T S+1}$

Where $T=\frac{V}{Q}$ is the time constant of the furnace, $K=\frac{1}{Q \rho C}$ is a static gain.

- Consider the transfer of heat into external medium as follows:

$H_{3}=h S_{w}\left(\theta-\theta_{s p}\right)$

Where: $h$ is the coefficient of heat transfer, $S_{w}$ is the external surface of furnace, and $\theta_{s p}$ is the ambient temperature. $\left(\theta-\theta_{s p}\right)$ is the difference between the temperature of the surface and the temperature of external medium.

The balanced equation after adding the heat losses is given as follows

$\rho C V \frac{d \theta}{d t}=H_{1}-H_{2}-H_{3}$

Substituting Eq.(3) into Eq.(4) we get

$T \frac{d \theta}{d t}+\theta=K_{l} \theta_{s p}+K H_{1}$

Where $K_{l}$ is a static gain for disturbance.

- The heat capacity of the walls of the furnace is to be taken into consideration in the model. The walls of the furnace has a volume $V_{W}\left(\mathrm{~m}^{3}\right)$, the material of the wall has density $\rho_{W}$ and a specific heat capacity $C_{W}[2,3]$.

The balance equation for the furnace space $[6,7]$

$$
\rho C V \frac{d \theta}{d t}=H_{1}-Q \rho C \theta_{2}-h_{w} S_{w}\left(\theta-\theta_{w}\right)
$$

Where $h_{w}$ is the heat transfer coefficient of the walls, $\theta_{w}$ is the wall temperature.

The balance equation for the walls can be represented by

$\rho_{w} C_{w} V_{w} \frac{d \theta_{w}}{d t}=h_{w} S_{w}\left(\theta-\theta_{w}\right)-h S_{w}\left(\theta_{w}-\theta_{s p}\right)$

Substituting these assumptions $\theta_{2}=\theta$, variables $H_{1}$ as input and $\theta$ is considered as output variable, the wall temperature $\theta_{W}$ can be derived as follows:

$\theta_{w}=\frac{1}{h_{w} S}\left(\rho C V \frac{d \theta}{d t}-H_{1}+Q \rho C \theta\right)$ 
Substituting Eq.(8) into Eq.(6) the furnace transfer function equation can be written as follows:

$T_{I} T_{2} \frac{d^{2} \theta}{d t^{2}}+\left(T_{I}+T_{2}\right) \frac{d \theta}{d t}+\theta=K H_{I}+K_{I} \frac{d H_{I}}{d t}+K_{2} \theta_{\mathrm{sp}}$

Eq.(9) in laplace transform is as follows [1,2]

$\theta(S)=\frac{\left(K+K_{1} S\right) H_{1}(S)+K_{2} \theta_{s p}(S)}{T_{1} T_{2} S^{2}+\left(T_{1}+T_{2}\right) S+1}$

Where, $T, T_{1}, T_{2}, K, K_{1}$ and $K_{2}$ are constants which are calculated by the use of the parameters of the heat transfer model. Eq. (10) represents the dynamic model of the furnace with heat losses in the surrounding. Figure (2) represents a block diagram of Eq. (10). The two inputs are ambient temperature $\theta_{s p}$ and the input heat flow $H_{l}$ and a single output $\theta$.

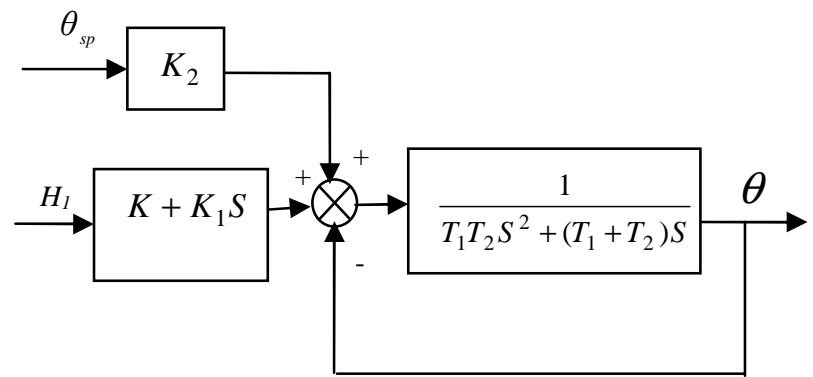

Fig. (2) Heat transfer model for the electrical arc furnace

\subsection{Summary of the Heat Transfer Modeling Parameters}

The parameters of the heat transfer model can be derived by the use of Eq. (1) to Eq. (10) and are shown in Table [1] as follows:

Table [1] Heat transfer model parameters

\begin{tabular}{|l|l|}
\hline Parameter & Math calculation of parameter \\
\hline$T_{1} T_{2}$ & $\frac{\rho C V \rho_{w} C_{w} V_{w}}{h_{w} S_{w}\left(\rho C Q+\frac{h \rho C Q}{h_{w}}+h S_{w}\right)}$ \\
\hline$T_{1}+T_{2}$ & $\frac{\frac{\rho C V \rho_{{ }_{w} C_{w} V_{w}}^{h_{w}}+\rho_{w} C_{w} V_{w}+\rho C V+\frac{h \rho C V}{h_{w}}}{\rho C Q+\frac{h \rho C Q}{h_{w}}+h S}}{}$ \\
\hline$K$ & $\frac{1+h / h_{w}}{\rho C Q+\frac{h \rho C Q}{h_{w}}+h S_{w}}$ \\
\hline$K_{I}$ & $\frac{\rho_{w} C_{w} V_{w}}{h_{w} S_{w}\left(\rho C Q+\frac{h \rho C Q}{h_{w}}+h S_{w}\right)}$ \\
\hline$K_{2}$ & $\frac{h S_{w}}{\left(\rho C Q+\frac{h \rho C Q}{h_{w}}+h S_{w}\right)}$ \\
\hline
\end{tabular}




\section{ARC FURNANCE ELECTRICAL SYSTEM}

The moving of the electrodes inside the arc furnace up and down above the slag creates the arc phenomenon. As the electrodes approach the slag, a huge value of current jumps from the electrodes to the slag. The arcing distance depends mainly on the magnitude of the input voltage. The heating power $P_{h i}$ of the arc for electrode $i$ depends on the value of the voltage and the conductance $G_{i}$ of the arc.

$P_{h i}=V_{\text {arci }}^{2} G_{i}$

The conductance of the arc for electrode $i$ depends on the physical properties of the raw materials and the geometrical dimensions of the arc of electrode i. This is given as:

$G_{i}=\sigma \frac{a_{i}}{\ell_{i}}$

Where $\sigma$ is the conductivity of the material being heated, $a_{i}$ and $l_{i}$ are the geometrical dimensions of the body. The electrical conductivity of the raw materials is varying creates the gas mixture in the furnace. The column path depends on the ratio $a_{i} / \ell_{\mathrm{i}}$ which is relatively large. According to the above analysis, the gas mixture in the furnace creates the arc resistance. Therefore to maintain a given power according to specified heating conditions, it is necessary to change the voltage supplied in wide range.

The equation of the source voltage transient response of the electrical arc furnace is given as:

$$
V_{s}=L \frac{d I}{d t}+I R+V_{a r c}
$$

Where $V_{s}$ voltage source, $V_{\text {arc }}$ arc voltage and $L, R$ are inductance and resistance of the conductor.

The practical difficulty in mounting sensors and devices deep is inside the furnace that makes the process unsuited for most direct measurements. A related temperature to electrical conductance and current inside the furnace can be measured and controlled as control variables which are the $V-I$ characteristic inside the arc furnace. The conductance in the furnace as function in temperature is given as follows [1];

$G(\theta)=G_{0}(1-\exp (0.5-\theta / 100)$

Where $G_{0}$ is the conduction at $25^{\circ}$

\subsection{Composing the Heat Transfer Model with Electrical System}

There are two subsystems in the electric arc furnace EAF. The first is the heat transfer subsystem (discussed in section 2), the other one is the electrical parts. The next step is to link these two subsystems. To do this, the following steps are taken to make the complete electrical arc furnace model:

a. The input of the heat transfer model is electrical power.

b. The heat transfer model output is temperature inside the furnace. 
c. The temperature inside the furnace affects the electrical resistance of the furnace.

d. The resistance inside the furnace affects the electrical parameters inside the furnace such as voltage under arc, current and power delivered to the furnace.

e. The electrical power depends on the voltage applied to the arc furnace, resistanceinductance of the conductors and the resistance-inductance inside the furnace.

f. Neglect the chemical reaction inside the furnace.

\subsection{Voltage-Current Ratio as a Control Variable in the Arc Furnace}

Figure (3) shows the closed loop system of the EAF equipped with PID control. The input to the controller is $V-I$ characteristic and the output of the furnace is the conductance as a function in $\theta$.

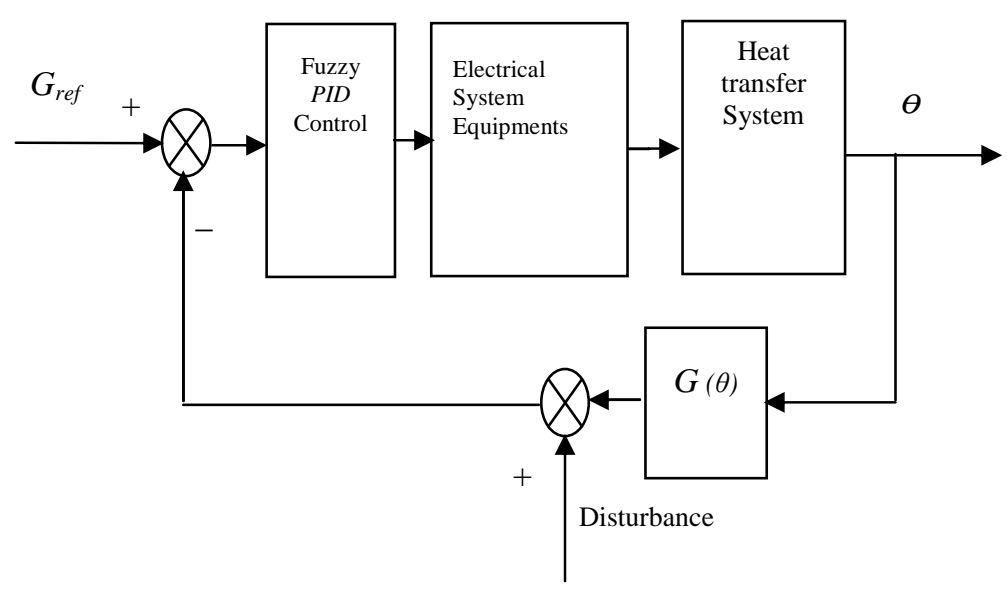

Fig. (3) Closed loop system of the EAF with PID control.

\section{FUZZY LOGIC CONTROLLER FOR SUBMERGED ARC FURNANCE}

\subsection{Classical Fuzzy Logic Controller for EAF}

In this section the fuzzy logic technique is used as a $P D$ controller as shown in Fig. (4).The parameters of the EAF system under control are the temperature of the arc furnace and the input electrical power. In this study, the output of the arc furnace is considered as the $V-I$ characteristic as mentioned in section 3. This output is used as input to the fuzzy logic controller. The input to the hydraulic system is the output of the fuzzy $P D$ controller. The hydraulic system is called a holder and is used to move the electrodes up and down to adjust their positions. The parameters $F_{e}, F_{e^{\prime}}$ and $F_{u}$ stand for scaling factors of the error $e$, rate of error $e^{\prime}$ and the output of the controller, respectively. The inputs to the fuzzy logic controller are selected to be the error of the $V-I$ characteristic which is called $e$ and the rate of the error $e$. Sampling signal for input controller equation is to be written as follows: 


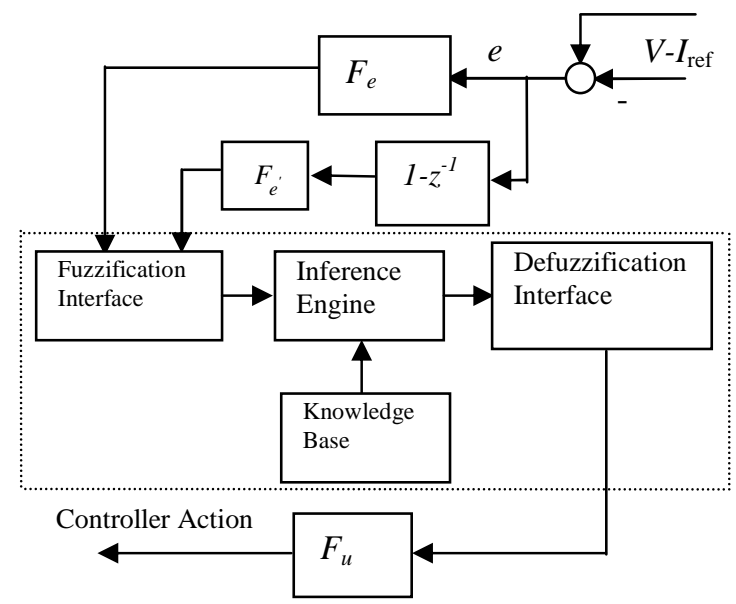

Fig. (4) PD controller I/O description

$$
\begin{aligned}
e^{\prime}(k) & =\left(\frac{e(k)-e(k-1)}{\Delta \tau}\right) \\
e^{\prime}(k) & =e(k)\left(\frac{1-z^{-1}}{\Delta \tau}\right)
\end{aligned}
$$

Where $\Delta \tau$ is the sampling interval (in our study equals to 0.001 ). The design of a fuzzy logic controller passes through the following stages: selection of input/output variables and their quantization in fuzzy sets, this stage called fuzzification; selection of the inference method; selection of the defuzzification technique.

\subsection{Fuzzification}

Having decided the inputs to the fuzzy logic controller, the next step is the selection of the membership functions to be associated with the input/output variables, where the input crisp variables $e(k)$ and $e^{\prime}(k)$ are converted to fuzzy variables. Figure (5) shows the membership functions used in this study. One normalized universe of discourse (-1, 1) for $e, e^{\prime}$ and the output variable $u_{E A F}$ is used. Each fuzzy universe of discourse is divided into eleven fuzzy sets:

- $\quad N L$ negative large

- $\quad N B$ negative big)

- $N M$ negative medium

- $\quad N S$ negative small

- $\quad N Z$ negative zero

- $Z$ zero

- $\quad P Z$ positive zero

- $\quad P S$ positive small

- $\quad P M$ positive medium

- $\quad P B$ positive big

- $P L$ positive large 


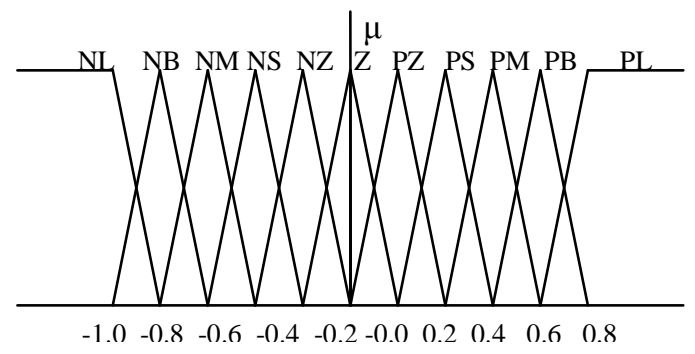

Fig. (5) Fuzzy membership function

\subsection{Rules Creation and Inference}

As stated before, the inputs to the fuzzy logic controller are the error $e$ and the rate of the error $e^{\prime}$. For a system of two control variables with eleven linguistic variables in each range as explained in section 4.2, this leads to an $11 \times 11$ decision table as shown in Table [2]. A set of rules which based on the decision table defines the relation between the input and output of the fuzzy variables $e$ and $e^{\prime}$ produced by the fuzzification stages. These are then processed by an inference engine that executes a set of control rules. The inference engine maps the input variable to the universe of discourse of the output variable. A typical rule has the following structure:

If $(e)$ is $P S$ and $(e)$ is $P M$ then $\left(u_{E A F}\right)$ is $P M$

Fuzzy rules are connected using $A N D$ operator and it was defined as minimum value between $\mu(e)$ and $\mu\left(e^{\prime}\right)$. Applying the operator $A N D$ to the rule given by Eq. (17), the minimum value between $\mu(e)$ and $\mu\left(e^{\prime}\right)$ can be derived. Finally the corresponding output membership function for the rule defined by Eq. (17) is calculated by clipping the corresponding output triangle membership function (i.e. $P M)$. This procedure is carried out for all the rules of the decision table shown in Table [2] and for every rule an output membership function is obtained. Fig.(6) shows the flow chart of the digital computer program used for simulation of an EAF provided with fuzzy PID controller.

Table [2] Rules creations table

\begin{tabular}{|c|c|c|c|c|c|c|c|c|c|c|c|c|}
\hline & \multicolumn{11}{|c|}{$\overrightarrow{e^{\prime}}$} \\
\hline & & NL & NB & NM & NS & $\mathbf{N Z}$ & $\mathbf{Z}$ & $\mathbf{P Z}$ & PS & $\mathbf{P M}$ & PB & PS \\
\hline \multirow{11}{*}{$\boldsymbol{e}$} & $\mathbf{N L}$ & & & & & & & & & & $\mathbf{N Z}$ & $\bar{Z}$ \\
\hline & NB & & & & & & & & & $\mathbf{N Z}$ & $\mathbf{Z}$ & $\mathbf{P Z}$ \\
\hline & NM & & & & & & & & $\mathrm{NZ}$ & $\mathbf{Z}$ & $\mathbf{P Z}$ & \\
\hline & NS & & & & & NM & NS & $\mathrm{NZ}$ & $\mathbf{Z}$ & $\mathbf{P Z}$ & & \\
\hline & $\mathbf{N Z}$ & & & & $\mathbf{N M}$ & NS & NZ & $\bar{Z}$ & $\mathbf{P Z}$ & $\overline{\text { PS }}$ & $\mathbf{P M}$ & \\
\hline & $\mathbf{Z}$ & & & $\mathbf{N M}$ & NS & $\mathbf{N Z}$ & $\bar{Z}$ & $\mathbf{P Z}$ & PS & $\overline{\mathbf{P M}}$ & & \\
\hline & $\mathbf{P Z}$ & & & NS & $\mathbf{N Z}$ & $\mathbf{Z}$ & $\mathbf{P Z}$ & PS & $\mathbf{P M}$ & & & \\
\hline & PS & & & $\mathrm{NZ}$ & $\mathbf{Z}$ & $\mathbf{P Z}$ & PS & $\mathbf{P M}$ & & & & \\
\hline & $\mathbf{P M}$ & & $\mathbf{N Z}$ & $\bar{Z}$ & $\mathbf{P Z}$ & PS & $\mathbf{P M}$ & & & & & \\
\hline & PB & & $\mathbf{Z}$ & $\mathbf{P Z}$ & PS & $\mathbf{P M}$ & & & & & & \\
\hline & PL & $\mathbf{Z}$ & $\mathbf{P Z}$ & PS & PM & & & & & & & \\
\hline
\end{tabular}




\subsection{Defuzzification}

It is necessary to transform the implied fuzzy set to a crisp output by the center of gravity technique as given by the Eq. (18), where $v_{i}$ is the numerical output at the ith number of rules and $\mu\left(v_{i}\right)$ corresponds to the value of fuzzy membership function at the ith number of rules. The summation is from one to $\mathrm{n}$, Where $n$ is the number of discrete values on the universe of discourse and $\mu$ is the membership grade of the element $v_{i}$ in the universe of discourse [24].

$$
u_{E A F}=\frac{\sum_{i=1}^{n} v_{i} u\left(v_{i}\right)}{\sum_{i=1}^{n} u\left(v_{i}\right)}
$$

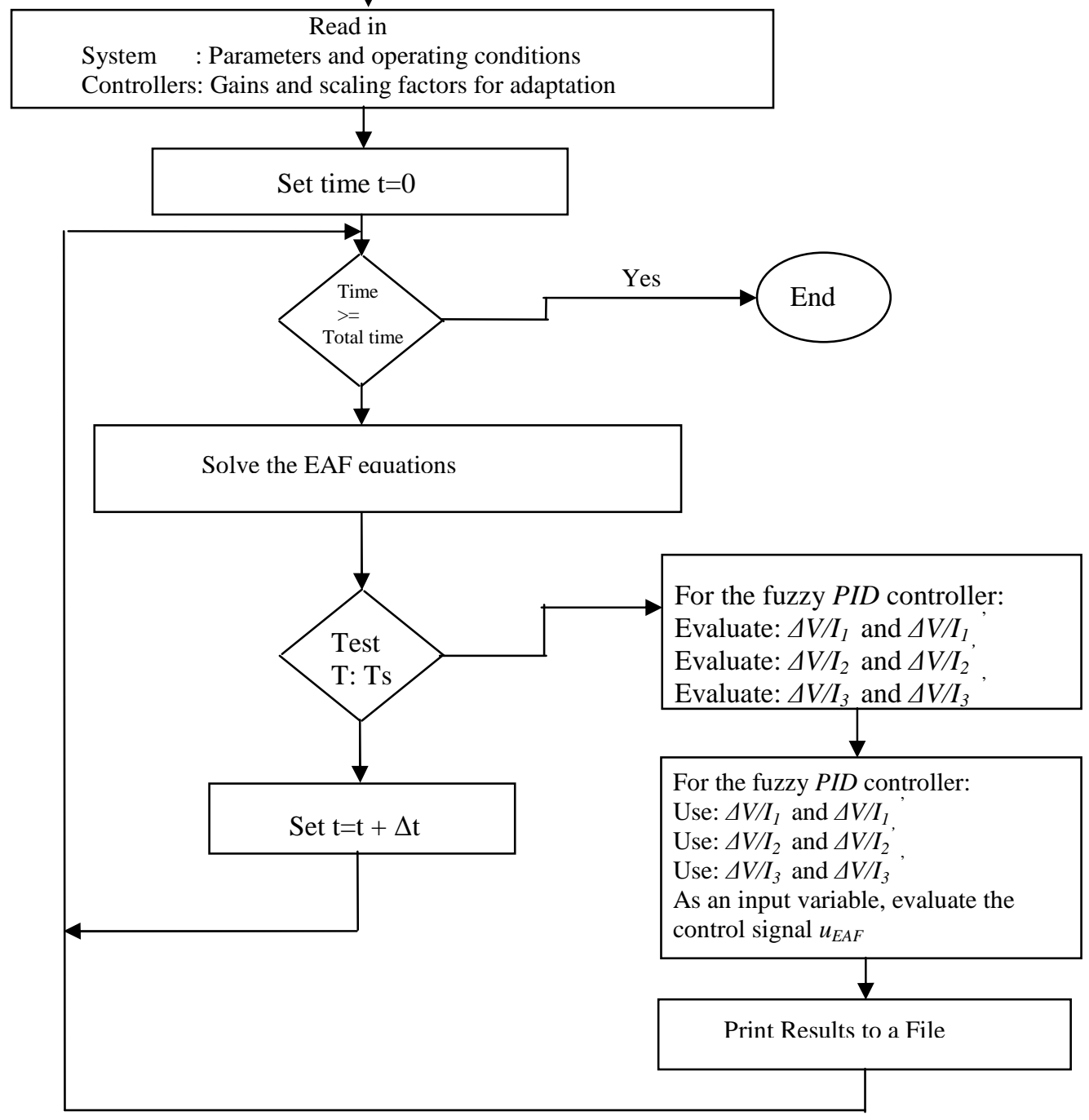

Fig. (6) Flow chart of the computer program used for simulation of an EAF provided with fuzzy PID controller 


\section{Proposed Fuzzy PID Controller for a Submerged ArC FERROSILICON FURNACE}

The input-output relation of the conventional PID controller is given as;

$u=K_{p} e+K_{I} \int e d t+K_{D} e$

The performance of that controller is determined by adjusting the parameters $K_{P}, K_{I}$ and $K_{D}$. The proportional parameter can guarantee the fast response of the control system, the integral parameter can eliminate the steady state error of the control system, and the derivative parameter can increase the damping of the control system. The fuzzy logic controller explained in section 4 is approximately behaved like a parameter time varying $P D$ controller. But obviously, there would be steady state error by using fuzzy $P D$ type controller. The input-output relation of the fuzzy $P D$ type controller can be approximated by [25];

$u_{E A F}=A+P e+D e^{\prime}$

The integral property of the fuzzy logic controller can be handled by implementing the integration of the system's error through the inputs of the fuzzy logic controller. The observation of the system's integral error is very difficult task in practice because more fuzzy control rules are needed. Hence, it is better to design a fuzzy controller by using the outputs of the fuzzy $P D$ controller. Utilizing the output relation given by Eq. (20), a fuzzy PID controller can be designed. Let an integrator be connected serially with a portion of the output of the fuzzy $P D$ controller as shown in Fig. (7). The structure of the proposed fuzzy controller is simply connected the $P D$ type fuzzy controller together in parallel with an integrator. The output of the fuzzy $P I D$ controller considering $\alpha$ as the weight on the $P D$ type, and $\beta$ as the weight on the $P I$ type can be approximated by the following [25];

$u_{E A F}^{\prime}=\alpha u+\beta \int u d t$

By substituting Eq. (21) into Eq. (20), the following equation can be obtained;

$u_{E A F}^{\prime}=\alpha\left(A+P e+D e^{\prime}\right)+\beta \int\left(A+P e+D e^{\prime}\right) d t$

Rearranging Eq. (22) yields

$u_{E A F}^{\prime}=\alpha A+\beta A t+(\alpha P+\beta D) e+\beta P \int e d t+\alpha D e^{\prime}$

Considering the scaling factors used in section 4.1, Eq. (23) can be written as;

$u_{E A F}^{\prime}=\alpha A+\beta A t+(\alpha P+\beta D) F_{e} e+\beta F_{e} P \int e d t+\alpha D F_{e} e^{\prime}$

Eq. (24) behaves like a time varying PID controller, its equivalent to proportional plus integral plus derivative control and the parameters are simply given as follows;

$K_{P=}(\alpha P+\beta D) F_{e}, K_{I}=\beta F_{e} P, \quad K_{D}=\alpha F_{e} D$

For $P I$ controller

$\alpha=0, \beta>0$

$u=\beta A t+\beta F_{e} \cdot D e+\beta F_{e} P \int e d t$ 
For $P D$ controller

$\alpha>0, \beta=0$

$u=\alpha A+\alpha F_{e} P+\alpha F_{e} e^{\prime}$

The integral property of the fuzzy controller can be handled by implementing the integration of the system's error through the inputs of the fuzzy $P D$ controller discussed in section 4 . The observation of the system's integral error is very difficult task in practice because more fuzzy control rules are needed. Hence, it is better to design a fuzzy controller by using the outputs of the fuzzy $P D$ controller. The output relation of the fuzzy $P D$ controller can be used in designing a fuzzy $P I D$ controller. Let an integrator be connected serially with a portion of the output of the fuzzy $P D$ controller as shown in Fig. (6). The structure of the proposed fuzzy controller is simply connected the fuzzy $P D$ controller together in parallel with an integrator. The output of the controller can be approximated by

$u_{E A F}^{\prime}=\alpha u_{E A F}+\beta \int u_{E A F} d t$

Symbol $\alpha$ and $\beta$ are the weight on the fuzzy $P D$ and $P I$ controller as defined before. The values of $\alpha$ and $\beta$ are chosen in our study case as 5.0 and 1.0 respectively.

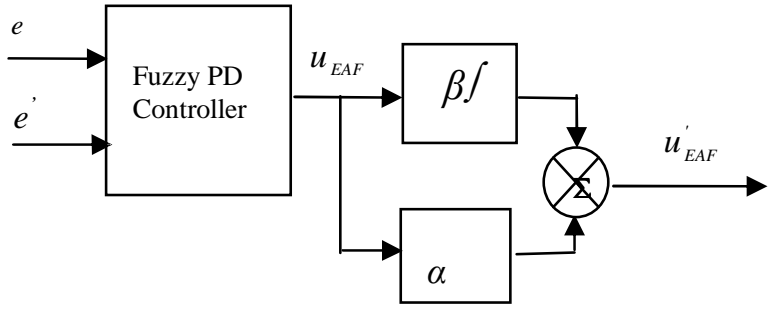

Fig.(7) PID controller I/O description

\section{Simulation RESULTS TO $10 \%$ DistuRBanCE IN THE IMPEDANCE OF THE RAW MATERIAL}

Standard ferrosilicon arc furnace was used for this study. The numerical values for the raw material used in this study are given in Table [A.1] and Table [A.2] in appendix A. For comparison, simulations with the proposed fuzzy PID controller and the conventional PID controller were run.

Figure (8) shows a $10 \%$ disturbance in the impedance of electrode 1 . The response shows a value of impedance equal to $2.44 \mathrm{~m} \Omega$ then due to disturbance it goes down to $2.23 \mathrm{~m} \Omega$. The drop in impedance means a significant change in the temperature of the furnace. The conventional PID controller raises the value to 2.44 $\mathrm{m} \Omega$ with higher overshoot, while the fuzzy PID controller raises gradually the value of impedance to $2.44 \mathrm{~m} \Omega$ with lower overshoot and fast settling time. Lower overshoot in the three phase submerged arc ferrosilicon furnace gives the benefit of no hazard in the transformer circuit due to the lower impedance. Figure (9) shows the corresponding current response of electrode 1 due to a $10 \%$ disturbance in the impedance of electrode 1. The steady state value of the current shows $58 \mathrm{KA}$, due to disturbance it reaches a higher value of $63.0 \mathrm{KA}$. With conventional PID it reaches $58 \mathrm{KA}$ with higher overshoot while with fuzzy PID it reaches $58 \mathrm{KA}$ with lower overshoot and fast 
settling time. Same results are obtained for electrodes two and three as shown in Figs. (10-13). In an EAF a large current fluctuations can cause the arc column to stretch to such an extent that the available power supply cannot maintain the arc. At this point, the arc extinguishes itself and reattaches to the electrode in such a manner as to minimize the initial ignition energy.

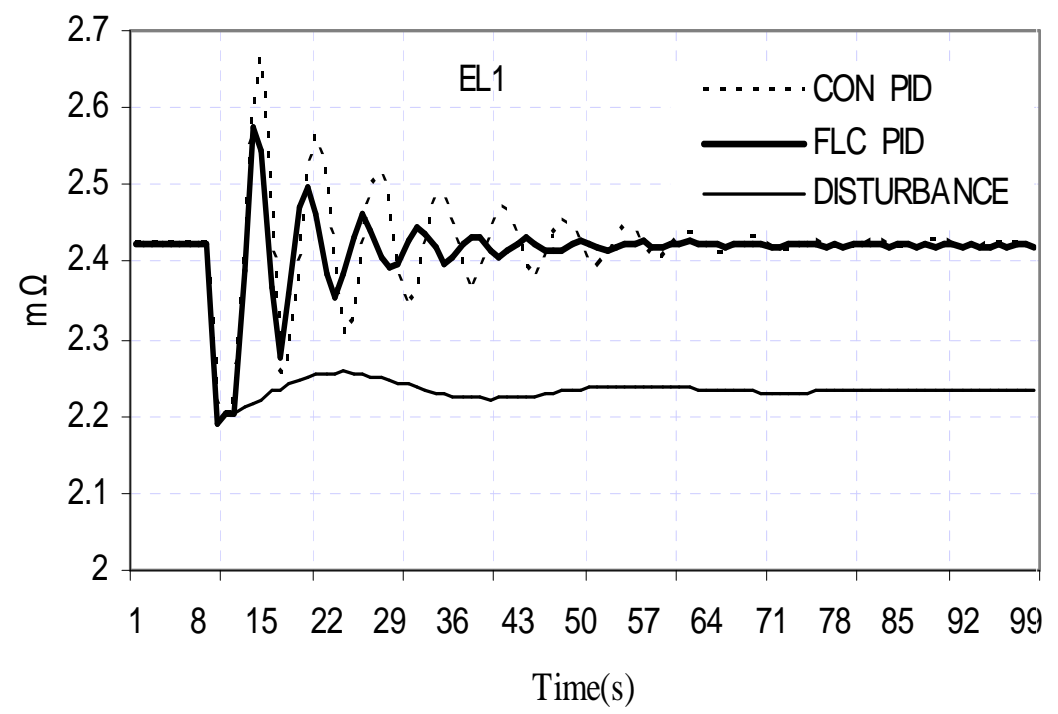

Fig. (8) Impedance responses of electrode 1

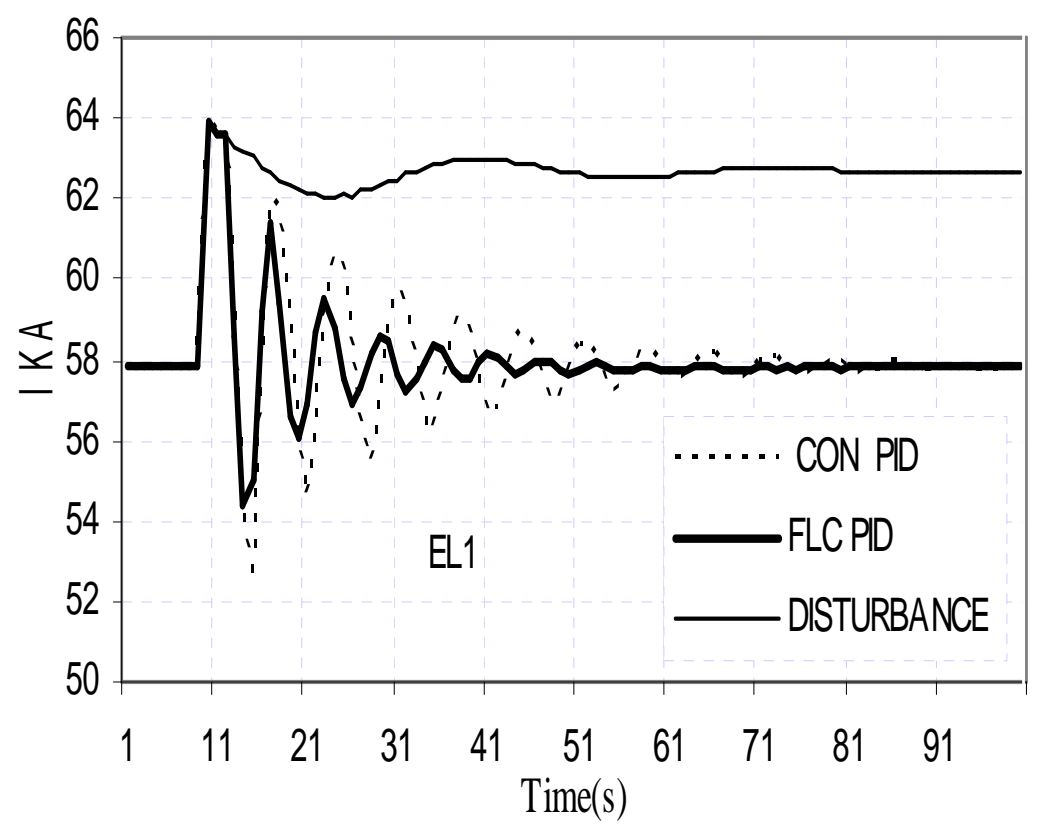

Fig. (9) Current responses of electrode1 


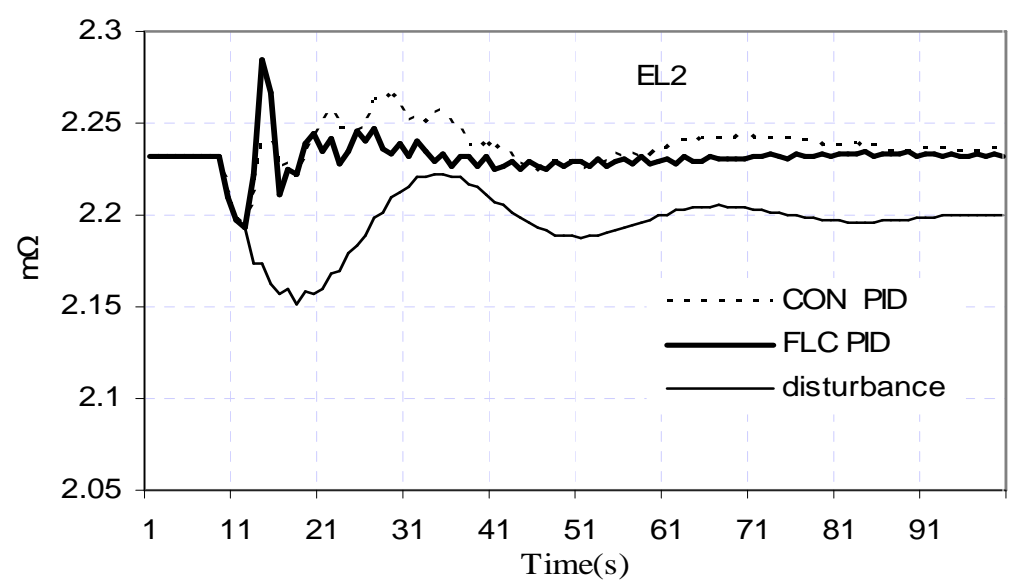

Fig. (10) Impedance responses of electrode 2

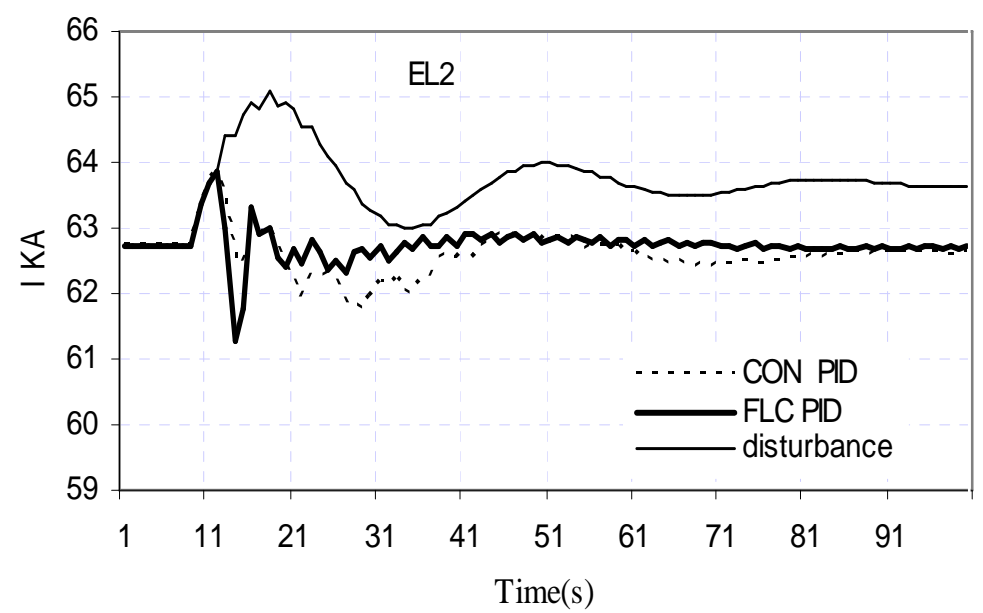

Fig. (11) Current responses of electrode2

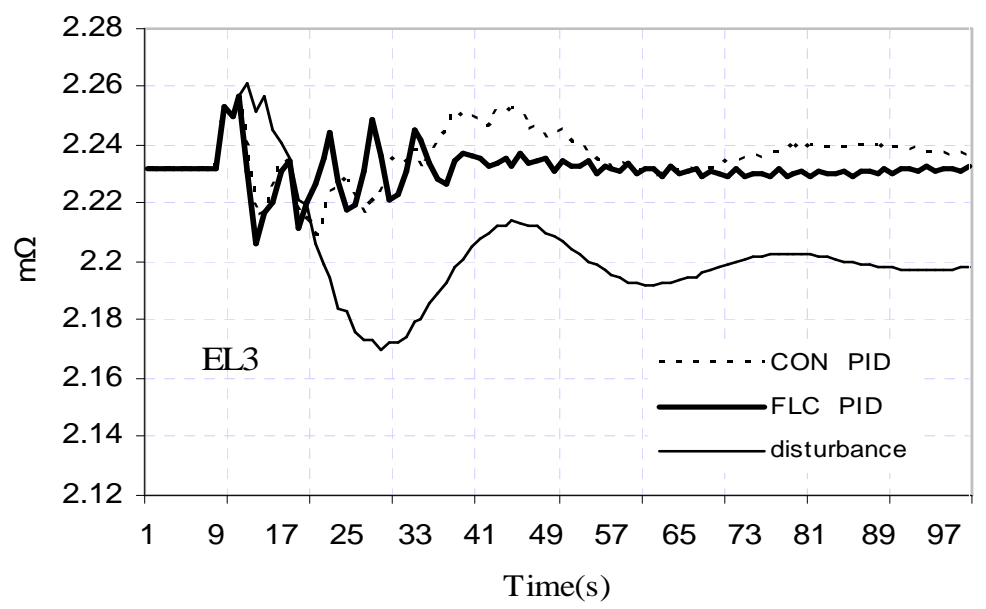

Fig. (12) Impedance responses of electrode 3 


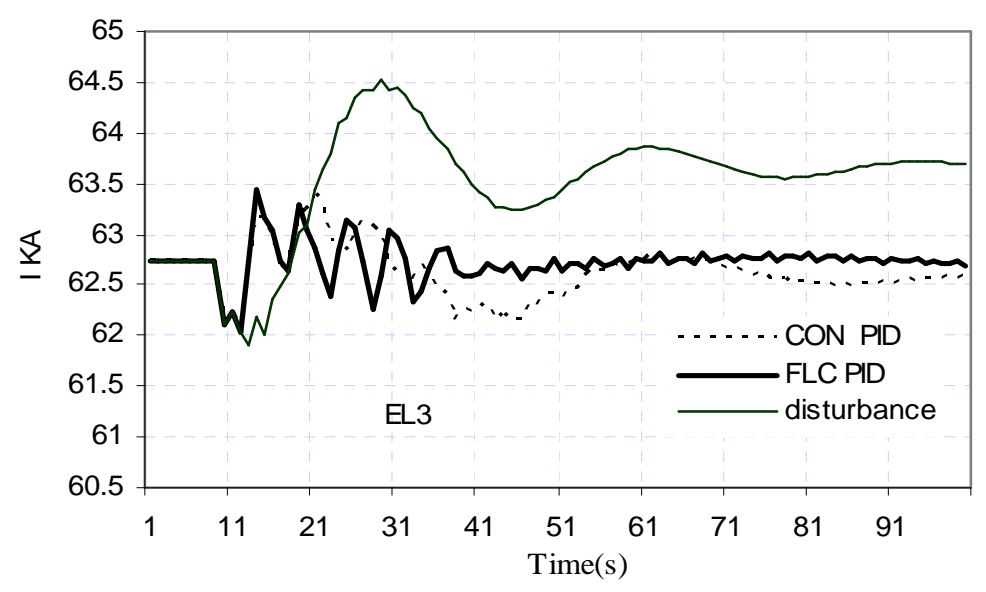

Fig. (13) Current responses of electrode3

\section{CONCLUSIONS}

The following conclusions can be drawn from the application of fuzzy logic to the control of arc ferrosilicon furnace as described in this paper:

a. Some aspects concerning the modeling and fuzzy logic control of the conductances and currents of the electrodes in an electrical arc furnace were presented.

b. The model forming a submerged arc ferrosilicon furnace was successfully solved using $\mathrm{C}++$ language program. When the study of the proposed fuzzy PID controller is compared with the conventional PID controller, the results obtained show that the performance of the proposed fuzzy PID controller might be more successful when the parameters $\alpha$ and $\beta$ are well adjusted.

c. The steady state error resulted from using fuzzy $P D$ controller in [23] is mainly eliminated using the proposed fuzzy PID controller.

d. The proposed fuzzy PID controller declares a better damping and settling time which improves the EAF system performance.

e. Fuzzy logic control is a promising control technique and would be effectively used for improved process control of arc ferrosilicon furnace.

f. The study will continue to increase the effectiveness of the proposed fuzzy PID controller by adding the adaptive property to it.

\section{REFERENCES}

[1] N. K. Batra, "Modeling of ferrosilicon smelting in submerged arc furnaces", Iron making \& Steelmaking, Vol. 30, No. 5, pp. 399-404, 2003.

[2] S. Hauksdottir, A. Gestsson, A. Vesteinsson, " Current control of a three-phase submerged arc ferrosilicon furnace", Control Engineering Practice, Vol. 10, No. 4, pp 457-463, 2002.

[3] S. Hauksdóttir, A. Gestsson, A. Vésteinsson, "Submerged-arc ferrosilicon furnace simulator; Validation for different furnaces and operating ranges", Control Engineering Practice, 6, 1035-1042, 1998. 
[4] J. Krishnaiah, C.S. Kumar, M.A. Faruqi, "Modelling and control of chaotic processes through their bifurcation diagrams generated with the help of recurrent neural network models. Part 2: An industrial study", Journal of Process Control, Vol. 16, pp. 67-79, 2006.

[5] S. -L. Jamsa A - Jounela, "Current status and future trends in the automation of mineral and metal processing", Control Engineering Practice, Vol. 9, 10211035,2001

[6] V. Singh, V. Tathavadkar, S. M. Rao, K.S. Raju, "Predicting the performance of submerged arc furnace with varied raw material combinations using artificial neural network", Journal of Materials Processing Technology, Vol. 183, pp. 111-116, 2007.

[7] L. Xiaohe, W. Yongshe, Y. Jie, "Digital model reference adaptive control for electrode regulator system of arc furnace based on inherit algorithm", Intelligent Control and Automation, Vol. 1, 2004.

[8] Z. Zeybek, "Role of adaptive heuristic criticism in cascade temperature control of an industrial tubular furnace", Applied Thermal Engineering, Vol. 26, pp. 152-160, 2006.

[9] B. Boulet, G. Lalli and M. Ajersch, "Modeling and Control of an Electric Arc Furnace, "Proceedings of the American Control Conference, Denver, Colorado June 4-6, 2003

[10] Gaber El- Saady "Adaptive static VAR controller for simultaneous elimination of voltage flickers and phase current imbalances due to arc furnaces loads", Electric Power Systems Research, Vol. 58, pp. 133-140, 2001.

[11] J. G. Bekker, I. K. Craig, P. C. Pistorius " Model predictive control of an electric arc furnace off-gas process", Control Engineering Practice, Vol. 8, pp. 445-455, 2000.

[12] Z. Hui and X. Wang, "Prediction Model of Arc Furnace Based on Improved BP Neural Network," Int. Conf. on Environmental Science and information Application Technology, ESIAT 2009, Vol.3, pp. 664-669, July 4-5, 2009.

[13] G. W. Chang, C.-I. Chen, and Y.-J. Liu, "A Neural-Network-Based Method of Modeling Electric Arc Furnace Load for Power Engineering Study," IEEE Trans. on Power Systems, Vol. 25, No.1, pp. 138-146, February 2010.

[14] Z. Wang, Q. Wu, T. Chai, " Optimal-setting control for complicated industrial processes and its application study", Control Engineering Practice, Vol. 12, pp. 65-74, 2004.

[15] R. Balan, V. Maties, O. Hancn, S. Stan, L. Ciprian, "Modeling and control of an electric arc furnace", Proceedings of the 15th Mediterranean Conference on Control\& Automation, Greece, 2007

[16] E. Grassi, K. Tsakalis "PID Controller Tuning by Frequency Loop-Shaping: Application to Diffusion Furnace Temperature Control", IEEE Transactions on Control Systems Technology, Vol. 8, No. 5, 2000.

[17] G. Ping, L. Ji-chao, and L. Xiao-he, "Direct adaptive fuzzy sliding mode control of arc furnace electrode regulator system," Chinese Control and Decision Conf., pp. 2776-2781, June, 17-19 2009.

[18] C. Kubata, H. Taskin, R. Artir, A. Yilmaz, "Bofy-fuzzy logic control for the basic oxygen furnace (BOF) ", Robotics and Autonomous Systems, Vol. 49, pp. 193-205, 2004. 
[19] W. Yuhua, "The Fuzzy Control of Electrode Regulator System", International Conference on Intelligent Human-Machine Systems and Cybernetics, Vol. 2, pp.49-52, 2009, China

[20] X.-H. Liu, R. Kuai, P. Guan, X.-M. Ye, and Z.-L. Wu, "Fuzzy-PID control for arc furnace electrode regulator system based on Genetic Algorithm," 2009 Int. Conf. on Machine Learning and Cybernetics, Vol.2, pp. 683-689, July 12-15, 2009.

[21] V. Kumar, K.P.S. Rana, V. Gupt, "A Real-Time Performance Evaluation of a Fuzzy PI + Fuzzy PD Controller for Liquid-Level Process ", International Journal of Intelligent Control and Systems, Vol. 13, No. 2, pp. 89-96, JUNE 2008.

[22] O. Karasakal, E. Yesil, M. Guzelkaya, I. Eksin, "Implementation of a New SelfTuning Fuzzy PID Controller on PLC ", Turk J Elec Engin, Vol.13, No.2, 2005.

[23] G. Shabib, "Modeling and Fuzzy Logic Control of a Submerged Arc Furnace", International Review of Automatic Control (IREACO), Vol. 4, No. 1, pp. 86-93, January 2011.

[24] P. J. King, E. H. Mamdani, "The application of fuzzy control systems to industrial processes", Automatica, Vol.13, No. 3, pp.235 -242, 1997.

[25] M. J. Patyra, D.M. Miynek, "Fuzzy logic implementation and applications", book, John wiley / Teubner 1996.

\section{APPENDIX A: NumERICAL DATA FOR SUBMERGEd ARC FERROSILICON FURNACE}

Table [A.1] shows the numerical values for the raw material, while Table [A.2] shows the numerical values for the walls of the ferrosilicon arc furnace.

Table [A.1] Numerical values of the components of the arc ferrosilicon furnace

\begin{tabular}{|l|l|l|}
\hline Material & Density ton $/ \mathrm{m}^{3}$ & Specific heat Mkal/ton.deg \\
\hline Quartz & 1.7 & 1.68 \\
\hline Coke & 0.53 & 0.2 \\
\hline $\mathrm{Fe}_{2} \mathrm{O}_{3}$ & 2.3 & 0.11 \\
\hline Average due to mass & 1.44325 & 1.09804 \\
\hline
\end{tabular}

Table [A.2] Numerical values of the components of the walls of the arc ferrosilicon furnace

\begin{tabular}{|l|l|}
\hline Property of walls & Numerical value \\
\hline Walls density ton $/ \mathrm{m}^{3} \quad \rho_{w}$ & 2.5 \\
\hline Walls specific heat MCal/ton.deg $C_{w}$ & 0.3 \\
\hline $\begin{array}{l}\text { Walls heat transfer coefficient } \mathrm{Mkal} / \mathrm{m}^{2} . \mathrm{h} . \mathrm{deg} \\
h_{w}\end{array}$ & 0.2 \\
\hline Walls volume $\mathrm{m}^{3} \quad V_{w}$ & 48.3693 \\
\hline Walls surface $\mathrm{m}^{2} S_{w}$ & 57.776 \\
\hline $\begin{array}{l}\text { Heat transfer coefficient between sphere and } \\
\text { wall Mkal/m } / \mathrm{m}^{2} \cdot \mathrm{h} . \mathrm{deg}\end{array}$ & 0.2 \\
\hline
\end{tabular}


The constants $T_{1}, T_{2}, K_{1}, K_{2}$ and $K$ of Eq. (9) can be calculated using the parameters of the heat transfer model and are found as follows:

$T_{1}=6.375287$ hour

$T_{2}=1.29634$ hour

$K_{1}=0.0970692$

$K_{2}=1.0$

$K=0.0643376$

The parameters of the PID controller are chosen as follows:

$K_{P}=1.2, K_{I}=1.0, K_{D}=0.169375$

The parameters of the fuzzy PID controller are chosen as follows:

$\alpha=5.0, \beta=1.0$

\section{نمذجة ومحاكاة الحاكمات اللامحدودة ثلاثية البارامترات لأفران الفيروسيلكون ذات الأقواس المغمورة}

فى هذا البحث تم دراسة وضع استراتيجية تحكم فى الطاقة الكهربية الداخلة لأفران الفيروسيلكون ثلاثية الأطوار . يوجد دخلين فى نظم التحكم اللامحدود التقليدي وهما إثارة الخطأ فى التوصيلية وكذلك معدل إثارة الخطأ فيها. عند مقارنة خرج الحاكمات اللامحدودة التقليدية مع النوع التتاسبى التفاضلى التقليدى وجد انه يحتاج إلى إعادة دقة فى حالة الاستقرار • لإعادة ضبط الحاكم اللامحدود التقليدى لابد من استخدام الحاكم اللامحدود من نوع ثلاثى البارامترات الذى يتميز بأنه حاكم لاخطى. يهنم هذا البحث فى إدخال خاصية التكامل للحاكم اللامحدود

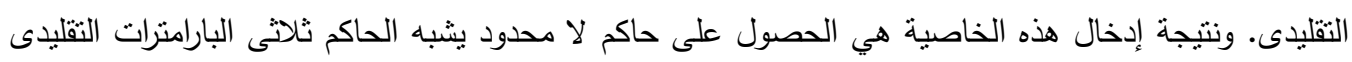

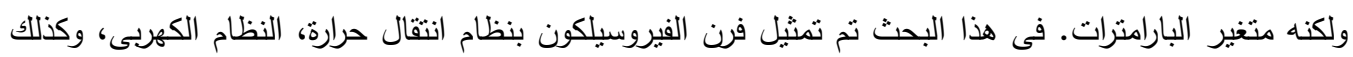
ديناميكية وضع الأقطاب وقد تم اختبار الحاكم المقترح عن طريق المحاكاة على فرن الفيروسيلكون باستخدام برنامج بلغة +C+C وكانت النتائج التى حصلنا عليها جيدة مقارنة باستخدام الحاكمات التقليدية ثلاثية البارامترات 